\title{
Fentanyl Matrix Transdermal Patch
}

National Cancer Institute

\section{Source}

National Cancer Institute. Fentanyl Matrix Transdermal Patch. NCI Thesaurus. Code C80067.

A transdermal formulation containing the synthetic phenylpiperidine opioid agonist fentanyl, with analgesic activity. Upon topical administration, fentanyl diffuses from the transdermal patch through the skin, is transported via the systemic circulation, and selectively binds to the mu-receptor in the central nervous system (CNS), mimicking the effects of endogenous opiates. Stimulation of the mu-receptor inhibits adenyl cyclase activity, induces opening of G-protein-coupled inwardly rectifying potassium (GIRK) channels, and blocks the opening of $\mathrm{N}$-type voltage-gated calcium channels, resulting in hyperpolarization and reduced neuronal excitability; in addition, neuronal release of neurotransmitters such as substance P, GABA, dopamine, acetylcholine and noradrenaline may decrease. 